DOI: http://dx.doi.org/10.5007/1980-3532.2016n15p55

\title{
Diretrizes curriculares para a Sociologia no ensino médio
}

\author{
Curriculum Guidelines for Sociology in high school
}

\author{
Ana Carolina Bordini Brabo Caridá \\ Instituto Federal de Santa Catarina - Câmpus São José \\ Professora de Sociologia \\ carolcarida@gmail.com
}

RESUMO: Esse artigo trata dos modelos de currículo no Brasil ao longo dos séculos XX e XXI, fazendo uma correlação com a presença ou não da sociologia no ambiente escolar e discute os fundamentos político-pedagógicos destes documentos oficiais. O trabalho traz reflexão sobre o currículo de sociologia no ensino médio, fazendo uma crítica à pedagogia das competências com base nos pressupostos da pedagogia histórico-crítica. Em suas considerações finais, o artigo estabelece relação entre as proposições neoliberais para as políticas educacionais e o cotidiano do professor.

Palavras chave: Ensino de Sociologia; Diretrizes curriculares; Pedagogia das competências

ABSTRACT: This article deals with the curriculum models in Brazil over the XX and XXI centuries, making a correlation with the presence or absence of sociology at school and discusses the politicalpedagogical foundations of these official documents. It reflects on the sociology curriculum in high school, analyzing critically the pedagogy skills based on the assumptions of historical-critical pedagogy. As concluding remarks, the article establishes a relationship between neoliberal proposals for educational policies and the everyday work of teachers.

Keywords: Sociology Teaching; Curriculum guidelines; Pedagogy skills

Originais recebidos em: 09/03/2016

Aceito para publicação em: 05/12/2016

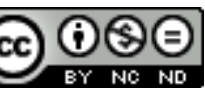

Este trabalho está licenciado sob uma Licença Creative Commons Atribuição-Uso NãoComercial-Vedada a criação de obras derivadas 3.0 Unported License. 


\section{Introdução}

Após longos anos de luta pela reintrodução da sociologia no currículo do ensino médio, ela passa a figurar em um contexto que impede o desenvolvimento de algumas de suas potencialidades educativas. A conquista pelo seu espaço nas escolas se dá no momento histórico em que a pedagogia das competências se afirma como proposta político-pedagógica dominante.

Suas diretrizes curriculares são expressão do contexto político e das ideias pedagógicas difundidas pelos órgãos oficiais. Sua presença na grade curricular das escolas ainda não se consolidou plenamente e é questionada por setores políticos ${ }^{1}$. Segundo Jinkings (2007):

Nos dias de hoje, os desafios relativos ao ensino de Sociologia nas escolas, estão fortemente enredados a questões sociais mais amplas, que acompanham as transformações contemporâneas do capitalismo e atingem com gravidade a educação brasileira e seu sistema público de ensino. Nas suas particularidades, advindas das especificidades do trabalho pedagógico com as ciências sociais, a atividade docente com a disciplina de Sociologia no ensino de nível médio no país é também intensamente afetada pelos problemas estruturais de uma sociedade desigual, na qual ainda se reivindica a universalização da educação básica. (JINKINGS, 2007, p. 115)

Este artigo tem como objetivo geral traçar um paralelo entre os currículos oficiais brasileiros e a presença ou não da sociologia no cotidiano escolar tomando como base as distintas reformas educacionais ao longo dos séculos XX e XXI. Para tanto discutimos os fundamentos político-pedagógicos que norteiam a obrigatoriedade/desobrigatoriedade da disciplina em distintos períodos históricos. Sinteticamente, pode-se dizer que a disciplina esteve presente em apenas três modelos de currículo, são eles: tradicional, escolanovista e neoescolanovista ${ }^{2}$ (pedagogia das competências); estando ausente ao longo da Ditadura Civil-Militar (pedagogia tecnicista).

\footnotetext{
${ }^{1}$ Corre no Congresso Nacional projeto de lei do deputado federal Izalci (PSDB) solicitando a retirada das disciplinas de Sociologia e Filosofia do ensino médio (PL 6003/13). O deputado se justifica afirmando que suas implementações como disciplinas obrigatórias tem sido difíceis, com pouca carga horária e que elas podem ser lecionadas no interior das demais disciplinas da área de ciências humanas. Link para o PL: http://www.camara.gov.br/proposicoesWeb/fichadetramitacao?idProposicao=585581 (acesso em 14/01/2014). Além desta iniciativa tramita na Câmara dos Deputados a medida provisória (MP746/2016) que propõem a retirada da obrigatoriedade do ensino de Sociologia e de Filosofia e sugere a diluição das disciplinas no interior das áreas de conhecimento. Link para a MP: http://www25.senado.leg.br/web/atividade/materias//materia/126992 (acesso em 13/12/2016).

2 Termo empregado por Saviani (2011) ao se referir as teorias educacionais que fundamentam a Reforma do Ensino Médio, a Lei de Diretrizes e Bases da Educação Nacional (LDB, 1996) e a fundamentação políticopedagógica das diretrizes curriculares.
} 
É interessante salientar que a disciplina de sociologia no contexto brasileiro aparece inicialmente nas escolas secundárias e em seguida nos cursos de nível superior. Santos (2002) divide a história do Ensino de Sociologia em três períodos, são eles:

- 1891-1941: institucionalização da disciplina no ensino secundário;

- 1942-1981: ausência da sociologia como disciplina obrigatória;

- 1982-2001: reinserção gradativa nos currículos oficiais ${ }^{3}$.

A presença da disciplina no ambiente escolar, apesar de seu caráter crítico e questionador, se dá atrelada as políticas educacionais dominantes, as quais modelam as práticas educativas deturpando possíveis veias emancipatórias. Em seguida, buscamos aclarar estas intersecções e discutir o que significa o currículo pautado na pedagogia das competências quando tratamos do ensino de Sociologia.

Michel Apple (2006), em sua obra Ideologia e Currículo, menciona que as escolas são permeadas por um conjunto de instituições políticas, econômicas e culturais, que contribuem para a reprodução das relações de classe. São “instituições que incorporam tradições coletivas e intenções humanas que, por sua vez, são os produtos de ideologias sociais e econômicas identificáveis" (APPLE, 2006, p. 84).

Afirma que a instituição escola faz uso de mecanismos de distribuição cultural na sociedade, e que, para compreendermos melhor este aspecto, devemos analisar a relação entre ideologia e conhecimento escolar. Apple (2006) aponta a relação entre cultura e controle no que se refere à promoção da desigualdade social, uma vez que as instituições escolares estão organizadas para distribuir diferentemente determinados tipos de conhecimento.

Os currículos oficiais são pautados em determinadas teorias pedagógicas difundidas pelo discurso dominante e por sua ideologia, as quais propõem os conteúdos a serem ensinados pelos educadores moldando os interesses científico-pedagógicos aos novos padrões do mundo do trabalho globalizado.

Partindo destas questões entendemos que o currículo de sociologia no ensino médio deve ser compreendido em um sentido totalizante, envolvendo todas as relações objetivas e subjetivas em que seu ensino se inscreve, levando em consideração desde os pressupostos de organização curriculares oficiais, até a organização do trabalho pedagógico empreendida pelo professor no contato diário com os estudantes.

\footnotetext{
${ }^{3}$ Santos (2002) no segundo capítulo de sua dissertação, A sociologia no ensino médio: o que pensam os professores da rede pública do Distrito Federal, discute as reformas educacionais ao longo do século XX e o papel da sociologia nos distintos períodos históricos.
} 


\section{O Ensino de Sociologia no currículo escolanovista}

A fim de situar as propostas de currículo que vigoraram no século $\mathrm{XX}$ trazemos as considerações de Saviani $(1997 ; 2007 ; 2011)$ no que se refere às teorias educacionais discutidas amplamente na academia e que se concretizaram ou não na prática escolar através de suas propostas pedagógicas. Apontamos a relação entre as ideias pedagógicas que fundamentaram a elaboração dos currículos oficiais e a presença da sociologia nestes contextos.

Primeiramente é necessário citarmos alguns pressupostos da teoria tradicional, para em seguida refletirmos sobre o contexto em que a sociologia é inserida nos cursos secundários durante a primeira república. Naquele momento o pensamento positivista estava em voga e havia a necessidade de afirmação de um novo governo e da identidade nacional. Tinha-se a burguesia como classe em ascensão no Brasil e as ideias iluministas eram traduzidas para o campo escolar. A leitura, a escrita, o cálculo e a educação jesuítica eram extremamente importantes para a dominação e domesticação do povo brasileiro. Assim, se defendia a transmissão do conhecimento com foco na figura do professor como aquele que detém a posse do saber acumulado pela humanidade.

A proposta tradicional segue como política educacional dominante até meados da década de 1920 e na década seguinte é lançado o Manifesto dos Pioneiros da Escola Nova, assinado por Fernando de Azevedo e outros intelectuais. Saviani (1997) demarca que existe uma relação intrínseca entre educação e política e combate a ideia de que a educação é um fenômeno técnico-pedagógico, aponta a educação como um ato político. O autor menciona que o escolanovismo rebaixou o nível de ensino das camadas populares e aprimorou a qualidade do ensino destinado as elites.

A proposta pedagógica dos escolanovistas faz uma crítica à centralidade do conhecimento e do professor. Newton Duarte (2010) aponta que a pedagogia do “aprender a aprender" sugere quatro posições valorativas. A primeira defende que é melhor aprender sozinho, pois o professor impede que o aluno desenvolva suas habilidades individuais, portanto, nega a transmissão de conhecimento. Em segundo lugar, aponta que para esta pedagogia o método é mais importante que o conhecimento acumulado pela sociedade, pois deve-se adquirir competências para buscar o conhecimento por si mesmo, sendo o processo mais importante que o produto, desvalorizando o conhecimento produzido. Em terceiro lugar, critica a supervalorização da vida, pois, toda atividade pedagógica deve ser desenvolvida a partir da prática 
cotidiana através de necessidades e interesses espontâneos. Por fim, menciona que, neste sentido, pretende-se formar indivíduos com alta capacidade adaptativa às exigências da sociedade e não indivíduos emancipados politicamente. Portanto, trata-se de uma pedagogia vinculada à ideologia de manutenção da sociedade capitalista.

Santos (2002) aponta que os escolanovistas estavam preocupados com os problemas sociais brasileiros e, no entanto, valorizavam a presença da disciplina de forma pragmática, ou seja, visando fins específicos. Neste momento o positivismo funcionalista ainda estava em alta e o intuito era $\mathrm{o}$ de formar cidadãos aptos a resolverem os problemas do país. O autor aponta que apesar da sociologia ter entrado no currículo com o advento da Escola Nova, ela não concretizou a função pragmática esperada. Permaneceu como disciplina ministrada de forma tradicional, não se aproximando dos pressupostos defendidos pelos escolanovistas. Era ensinada de forma fragmentada, através de aulas expositivas centradas na figura do mestre-escola, isto é, nem sempre o discurso oficial se afirma no contexto das instituições escolares.

Neste momento, as ciências sociais ainda não haviam se legitimado no país. Com relação ao seu ensino havia um distanciamento muito grande dos métodos e técnicas de pesquisa próprios das ciências sociais (MEUCCI, 2000). A sociologia entra como disciplina científica na Escola Livre de Sociologia e Política, em 1933, e nas Universidades de São Paulo e do Rio de Janeiro, em 1934. Naquele momento o pensamento social brasileiro estava voltado aos debates de caráter republicano e liberal e tinha o intuito de problematizar, através da teoria positivista, as questões de manutenção da ordem social:

\begin{abstract}
O incentivo ao ensino de ciências sociais no país, naquele contexto, respondia a interesses e preocupações práticas da intelectualidade liberal, com vistas à retomada da hegemonia política perdida após as revoluções de 1930 e 1932. (...) Desse modo, as ciências sociais ficavam reduzidas a uma espécie de "engenharia social", cuja finalidade seria a contenção dos conflitos sociais. (JINKINGS, 2007, p. 119)
\end{abstract}

Guelfi (2011) aponta que há um descompasso entre a constituição da sociologia como ciência e como disciplina escolar. Sua presença no currículo das escolas de nível médio se dá até 1941, quando ela é retirada do currículo pela Reforma Capanema durante o Estado Novo. Ou seja, tem-se menos de uma década de intersecção para um possível diálogo entre universidade, legisladores e escolas. Em 1942, a sociologia se ausenta do currículo e seu retorno começa a se dar em 1982, quarenta anos mais tarde. 


\section{As potencialidades do Ensino de Sociologia à luz de Florestan Fernandes}

Em 1954, no I Congresso Brasileiro de Sociologia o debate acerca da inserção da disciplina no ensino secundário toma fôlego e Florestan Fernandes demarca a importância de se estudar esta ciência não mais para legitimar a ordem social dominante, mas sim para questioná-la. Fernandes (1976) neste momento está preocupado com dois pontos chaves. Ele discute qual é a posição que o ensino secundário ocupa naquele momento histórico dentro do sistema educacional brasileiro, e, portanto, qual é a 'função' do ensino das ciências sociais nestas escolas. Para o autor o ensino da sociologia na escola secundária seria a maneira mais construtiva de divulgação dos conhecimentos sociológicos e sua difusão teria importância para o desenvolvimento da própria ciência sociológica.

Florestan Fernandes foi um sociólogo preocupado com as questões de sua época e defendia a escola pública e o ensino da sociologia. Para o autor era necessário pensar o ensino de sociologia dentro da estrutura educacional brasileira, ou seja, não se deixando cair na utopia de se pensar as potencialidades educativas da disciplina descoladas da situação real onde ela se insere. Valorizava a relação entre teoria e prática e afirmava que seu olhar sociológico começou a se desenvolver aos seis anos de idade quando sua racionalidade começou a aflorar e então ele passou a perceber o meio social em que estava inserido. Assim, Florestan acreditava que os jovens deveriam ter contato com a discussão sociológica, para que então pudessem refletir sobre seus contextos e lutar por melhores condições de vida e sociedade.

Florestan Fernandes esteve envolvido no contexto da elaboração das duas Leis de Diretrizes e Bases da Educação (LDB) que orientaram o ensino desde a década de sessenta até o momento presente. A primeira LDB data de 1961, quando o autor escreve a obra Educação e Sociedade no Brasil (1966), período em que o educador realiza a defesa da escola pública e da universalização de seu acesso. Mais contemporaneamente Florestan Fernandes participou ativamente na construção do capítulo sobre a educação na Constituição Brasileira de 1988 e contribuiu com a elaboração da atual LDB (1996).

Na década de 1960, em meio às lutas e efervescências sociais, fez sua defesa da escola pública e construiu uma teoria que deu base para problematizar o processo 
educacional. Florestan Fernandes (1966) entende a educação a partir da perspectiva materialista dialética, pois é impossível compreendê-la a partir de uma base "neutra" desarticulada dos processos sociais que permeiam os interesses dos governos vigentes na época. Assim, todo processo educativo tem um cunho formativo e esta premissa está presente nas políticas educacionais e nas intenções que permeiam estes processos.

A partir destas considerações, Florestan levanta três planos específicos de percepção e de explicação dos temas educacionais. O primeiro estaria vinculado ao conhecimento do senso comum, o segundo ao conhecimento propriamente pedagógico da situação educacional brasileira, e, por fim, ao conhecimento das conexões, estruturas e funções extrapedagógicas dos processos que ocorrem no seio das instituições educacionais ou do sistema de ensino da sociedade brasileira (FERNANDES, 1966). Na obra de Florestan Fernandes podemos perceber a influência dos padrões burgueses dando base aos pressupostos educativos da época. $\mathrm{O}$ autor assinala que os valores educacionais são ocultados pela ideologia dominante, onde o imaginário da classe burguesa tenta se legitimar impondo padrões de conformação com o estado atual das coisas.

Em 1964 se dá o Golpe Militar e em 1971, sob o governo do Presidente Médici a reforma educacional divide o ensino em $1^{\circ}$. e $2^{\circ}$. Graus. Esta reforma visava responder às necessidades do "milagre econômico", momento de entrada dos capitais estrangeiros no país. $\mathrm{O}$ intuito neste momento era o de formar uma força de trabalho barata para responder a estas necessidades. Aqui a pedagogia tecnicista toma força e o modelo curricular se centra na organização racional dos meios pela garantia da máxima eficiência. O lema então é "aprender a fazer" e os cursos secundários se transformam em cursos profissionalizantes. Neste momento a disciplina de sociologia é transformada em Organização Social e Política Brasileira (OSPB) e a disciplina de Filosofia em Educação Moral e Cívica (EMC). Florestan Fernandes (1989) aponta que este período impulsionou rápidas transferências de poder para educadores e técnicos, facilitou a extrema elitização organizacional e administrativa, justificou o controle e a espionagem e converteu os números em máscaras e mitos.

\section{O Ensino de Sociologia e a pedagogia das competências}

Com a dissolução do regime militar foi possível iniciar uma readequação da estrutura educacional brasileira. Em 1982, é revogada a obrigatoriedade dos cursos Revista Em Debate (UFSC), Florianópolis, volume 16, p. 55-68, 2016. ISSNe 1980-3532 
profissionalizantes e a discussão para o retorno da sociologia e da filosofia se reacende. Em 1988, com o advento da constituição, tem-se o início das reformas curriculares. Este período também é marcado pela disputa entre distintas correntes pedagógicas, de um lado as teorias marcadas pela influência do Consenso de Washington, marcando a presença da ideologia neoliberal e sua influência nos países em desenvolvimento, atravessando o plano educacional, e, de outro, as teorias críticas defendendo que a história não se encerra no capitalismo e que é necessário pensar propostas de superação deste modelo de sociedade.

Ainda na década de 1980 um grupo de professores da Faculdade de Educação da Universidade Estadual de Campinas (Unicamp), vinculados ao laboratório de História da Educação no Brasil (HISTEDBR), liderado pelo professor Dermeval Saviani, começam a pensar uma pedagogia que contrapõem os interesses das classes dominantes a partir dos interesses dos trabalhadores, valorizando o conhecimento produzido pela humanidade. Neste momento tem-se o germe do que posteriormente convencionou-se chamar de pedagogia histórico-crítica, uma pedagogia contra hegemônica que sugere uma reorientação da prática educativa.

Também neste mesmo período Florestan Fernandes publica alguns artigos em jornais de grande circulação no país, os quais posteriormente são compilados no livro $O$ Desafio Educacional (1989). Nesta obra, Florestan faz alguns paralelos entre o escolanovismo e o que ele chama de "Nova República", conceito pensado a fim de opor a ideia de "redemocratização" muito em voga na época pela classe política. Estava preocupado em pensar a revolução educacional. Afirma que a escola nova se afastou da realidade histórica e dos problemas do país, sendo utópica, pois pensou em meios para atingir fins educacionais ideais. Para ele o papel da educação era promover a descolonização, a revolução nacional e uma verdadeira revolução democrática (grifo nosso). Defendia que esta mudança deveria ocorrer dentro da escola. A revolução democrática seria um processo global de transformação da sociedade pela distribuição igualitária das oportunidades educacionais. A descolonização seria a auto emancipação cultural da escola, do sistema de ensino e da nação, enquanto a revolução nacional seria a liberação dos oprimidos através da expansão da capacidade criativa.

Refletindo sobre a construção da nova LDB, Florestan Fernandes menciona que o sistema educacional e de pesquisa deve ser a chave de interação de uma história mundial revolucionária, caso contrário ela visará ritmos ambíguos da educação para as elites, nos fazendo vassalos permanentes dos Estados Unidos, negando a soberania do 
Brasil como nação. Para ele a finalidade da educação deve ser a desobjetificação do ser humano e a autonomização da escola e da democracia igualitária e libertária em todas as formas de querer e de saber, buscando o entendimento recíproco, a solidariedade e a comunhão de valores ideais.

Neste contexto a pedagogia tecnicista dá lugar a pedagogia das competências, conceito extraído de concepções empresariais, as quais substituem o conceito de qualificação profissional pelo de competências, visto ser este de caráter mais abrangente, pois tem foco não apenas no que o trabalhador sabe executar em uma função, mas em como ele é visto como um profissional independente de ocupar um cargo em uma empresa ou não, ou seja, individualizando o sujeito.

Para Fleury e Fleury (2001) as competências agregam valor social e econômico para os indivíduos e para as empresas no que se refere a: "saber agir, saber mobilizar, saber transferir, saber aprender, saber se engajar, ter visão estratégica e assumir responsabilidades" (FLEURY; FLEURY, 2001, p. 188). Neste sentido, a escola tem o papel de formar os estudantes para que através das áreas de conhecimento eles possam adquirir estas qualidades tão valorizadas pelas grandes corporações.

Octavio Ianni proferiu uma palestra em 1985, ressaltando a importância da sociologia na escola e descreveu alguns caminhos básicos para os professores das ciências sociais em geral e, mais especificamente para os docentes em sociologia. Traçou como fundamento de uma metodologia do ensino da disciplina a discussão de que o real está sempre em movimento e que justamente este movimento é o que deve ser apreendido pelo professor e debatido com os alunos. Afirma que através da análise do movimento e da transformação é possível descortinar o senso comum e desmistificar o que se afirma como natural e imutável em certo momento histórico (IANNI, 2011).

Ianni (1997) problematiza a sociologia em si para pensar suas potencialidades e considera que esta ciência tem uma "vocação de autocrítica", o que contribui para que seus objetos de pesquisa estejam em constante transformação. O sociólogo afirma que houve muitas mutações do objeto sociológico nesta passagem de século e, deste modo, diante das metamorfoses desta ciência, a teoria se vê desafiada a reelaborar seus fundamentos básicos de análise da realidade social.

Retomando a presença da sociologia no currículo, entre as décadas de 1980 e 1990 alguns estados como São Paulo, Paraná, Minas Gerais, Rio de Janeiro, Pará, Santa Catarina e Rio Grande do Sul impulsionam o debate acerca da presença da sociologia como componente curricular obrigatório em nível nacional. A primeira proposta de 
conteúdos programáticos foi formulada em São Paulo ainda na década de 1980. Em 1991 tem-se a primeira tentativa de obrigatoriedade da disciplina no estado do Rio de Janeiro e em Santa Catarina e, em 1994, no Espírito Santo (SILVA, 2007).

Nesse contexto sociopolítico a disciplina de sociologia passa a figurar como componente transversal na matriz curricular. Em 1996 é instituída a nova Lei de Diretrizes e Bases da Educação Nacional (Lei $n^{\circ}$. 9394/96), marcando a entrada da pedagogia das competências no plano educacional brasileiro. Esta lei em seu artigo 36 propunha que ao final do ensino médio os alunos deveriam ter os conhecimentos de filosofia e sociologia, necessários ao exercício da cidadania. O texto deu margem a diferentes interpretações relativas ao lugar das disciplinas no sistema escolar.

Nos Parâmetros Curriculares Nacionais (PCNs, 1998), constava que os saberes das duas áreas de conhecimento poderiam estar presentes em outras disciplinas ou temas transversais, em vários estados resoluções firmaram as disciplinas como obrigatórias nos currículos. A presença disciplinar da Sociologia (e também da Filosofia) se fortalece com a lei federal $n^{\circ} 11.684$, de 2 junho de 2008. Esta lei altera o art. 36 da Lei no 9.394, de 20 de dezembro de 1996, que estabelece as diretrizes e bases da educação nacional, para incluir a Filosofia e a Sociologia como obrigatórias nos currículos das três séries do ensino médio.

Os PCN's (1998) demonstram desconhecer as potencialidades da disciplina, bem como sua abrangência como conhecimento científico. Mencionam que os conceitos das ciências sociais devem estar articulados com as demais áreas trabalhadas no ensino médio, como: língua portuguesa, educação física, matemática, biologia, história e filosofia.

Os conteúdos sociológicos não são abordados a partir de um viés crítico com relação ao mundo do trabalho. Não focam a questão no debate acerca do modo como a sociedade capitalista está organizada com seus conflitos e contradições. Não tratam da transformação e revolução social, mas sim de mudanças sociais através da participação cidadã e democrática. Não questionam em momento algum o regime democrático da forma como ele está organizado politicamente e economicamente. Trazem questões que envolvem a sociedade capitalista a partir de um olhar de enquadramento neste processo e não de questionamento de suas bases materiais. Apontam alguns conceitos da teoria crítica como ideologia e alienação, mas não problematizam a questão da desnaturalização da concepção de sociedade presente no senso comum no que se refere ao questionamento das práticas cotidianas inseridas num processo maior de globalização 
neoliberal. Trata-se de um documento que norteia alguns conteúdos e temas interessantes para serem abordados em sala de aula, mas que deixa a desejar no que se refere ao seu caráter político-pedagógico e aos fundamentos mais amplos que envolvem as ciências sociais como um todo.

As Orientações Curriculares Nacionais (OCNs, 2006) não propõem um conteúdo programático definido a ser trabalhado com os estudantes e nem se posicionam com relação as teorias didático-pedagógicas que respaldam o documento. Defendem que a sociologia é o espaço de realização das ciências sociais no ensino médio e que não há uma discussão consolidada na área, conteúdos consagrados a serem trabalhados no ensino médio. Partem da desnaturalização e do estranhamento como fundamentos epistemológicos de seu ensino.

Passados dez anos muitas pesquisas já foram desenvolvidas na área e inúmeros debates foram travados em eventos locais, regionais e nacionais. De fato, ainda não há conteúdos consagrados para o ensino da Sociologia, porém a partir do debate pedagógico que baseia as mais variadas formas de se abordar os conteúdos é possível questionar as políticas educacionais como um todo e pensar maneiras de como se trabalhar esta disciplina no cotidiano escolar para que ela faça sentido aos filhos da classe trabalhadora, principais sujeitos envolvidos ao longo do processo didáticopedagógico.

\section{Considerações finais}

Podemos dizer que as concepções neoliberais de educação permeiam o sistema escolar como um todo e estão presentes em toda a organização do ensino. Influenciam o currículo, o processo de ensino-aprendizagem e o trabalho docente. Nota-se que atualmente há um forte processo de precarização do trabalho que recai também no cotidiano do professor, o qual necessita lecionar muitas horas para conseguir suprir suas condições materiais de existência.

Com relação à proletarização do professor, Costa et al (2009) assinalam que a lógica do mercado invade a organização do trabalho na escola e uma das consequências deste processo é a alienação do trabalhador. Afirmam que o espaço hegemônico em que o professor atua é a escola capitalista, e que esta é o lugar de reprodução das ideologias e da força de trabalho. Deste modo, a educação adestra não só os estudantes como também os docentes, pois introduz o modus operandi do mundo do trabalho nas Revista Em Debate (UFSC), Florianópolis, volume 16, p. 55-68, 2016. ISSNe 1980-3532 
instituições escolares, uma vez que o Estado obriga o professor a exercer seu trabalho em condições precárias, configurando violência no ambiente de trabalho. Pode-se dizer que o Estado se esforça para alienar os docentes e os culpabiliza por sua má formação e qualificação profissionais frente aos problemas educacionais advindos do próprio modelo de organização escolar. O governo brasileiro assume as políticas educacionais impostas pelas agências internacionais, invertendo a lógica de reprodução do capital através do discurso e de seus pressupostos ideológicos.

Neste artigo abordamos a historicidade do currículo escolar brasileiro, visualizando a presença da sociologia no ambiente escolar em diferentes contextos. $\mathrm{O}$ ensino de Sociologia pode ser pensado à luz da pedagogia histórico-crítica, como contraponto ao modelo preconizado pela pedagogia das competências. As teorias educacionais, vinculadas a ação docente, podem dar mais sentido às práticas questionadoras do cotidiano quando atreladas a projetos político-pedagógicos que contribuem com a transformação social.

Trago esta discussão, pois acredito que o professor deve se situar politicamente e pedagogicamente antes de elaborar seu planejamento de ensino. A pedagogia históricocrítica aponta que a pedagogia das competências se apropria do discurso empresarial e visa individualizar os sujeitos nos processos mais amplos de inserção social, como o mercado de trabalho. Entende o trabalho como um princípio educativo e neste sentido, o trabalho docente como um trabalho intelectual que não separa o ato de produção do produto final do trabalho. Parte do concreto e não do ideal, valorizando os conteúdos como força material, contrariando os pressupostos do neoescolanovismo onde os conteúdos são pragmáticos e devem ser diluídos no interior das distintas áreas de conhecimento.

\section{Referências}

APPLE, Michael W. Ideologia e currículo. $3^{\text {a }}$ Ed. Porto Alegre: Artmed, 2006.

BRASIL. Lei de Diretrizes e Bases da Educação Nacional, 1996.

COAN, Marival. A sociologia no ensino médio, o material didático e a categoria trabalho. Dissertação de mestrado (Programa de Pós-Graduação em Educação/UFSC). Florianópolis, 2006. 
COSTA, Áurea; NETO, Edgard; SOUZA, Gilberto. A proletarização do professor: neoliberalismo na educação. São Paulo: Editora Instituto José Luís e Rosa Sunderman, 2009.

DUARTE, Newton. O debate contemporâneo das teorias pedagógicas. In: Formação de professores: limites contemporâneos e alternativas necessárias. São Paulo: Editora UNESP, 2010.

FERNANDES, Florestan. Educação e Sociedade no Brasil. São Paulo: Dominus, 1966.

O Ensino de Sociologia na escola secundária brasileira. In: A

Sociologia no Brasil. Petrópolis: Vozes, 1976.

Associados, 1989.

O Desafio Educacional. São Paulo: Cortez: Autores

FLEURY, Maria Tereza Leme; FLEURY, Afonso. Construindo o conceito de competência. In: RAC, Edição Especial, 2001.

GUELFI, Wanirley Pedroso. A sociologia como disciplina escolar no ensino secundário brasileiro: 1925-1942. Dissertação de mestrado (Programa de Pós-Graduação em Educação/UFPR). Curitiba, 2001.

IANNI, Octavio. A sociologia numa época de globalismo. In: L. Ferreira (org.). A sociologia no horizonte do século XXI. São Paulo: Boitempo, 1997.

O Ensino das Ciências Sociais no $1^{\circ}$ e $2^{\circ}$ graus. In: Caderno Cedes.

Campinas, v. 31, n. 85, set./dez. 2011.

JINKINGS, Nise. Ensino de sociologia: particularidades e desafios contemporâneos. In: Mediações, Londrina, v.12, n.1.,2007.

MEUCCI, Simone. A institucionalização da sociologia no Brasil: os primeiros manuais e cursos. Dissertação (Programa de Pós-Graduação em Ciências Sociais, Unicamp). Campinas, 2000.

ORIENTAÇÕES CURRICULARES NACIONAIS PARA O ENSINO MÉDIO. Conhecimentos de Sociologia. In: Ciências humanas e suas tecnologias/Secretaria de Educação Básica. Autores: Amaury César Moraes, Elisabeth da Fonseca Guimarães \& Nelson Dácio Tomazi. 2006.

ORIENTAÇÕES EDUCACIONAIS COMPLEMENTARES AOS PARÂMETROS CURRICULARES NACIONAIS (PCN+, Ensino Médio, Ciências Humanas e suas tecnologias). MEC. 2000.

PARÂMETROS CURRICULARES NACIONAIS PARA O ENSINO MÉDIO. Parte IV: Ciências Humanas e Suas Tecnologias. MEC. 1998.

SANTOS, Mario Bispo. A sociologia no ensino médio: o que pensam os professores da rede pública do Distrito Federal. Dissertação de mestrado (Programa de Pós-Graduação em Sociologia/Unb). Brasília, 2002. 
SAVIANI, Dermeval. Escola e Democracia: polêmicas do nosso tempo. $31^{\mathrm{a}} \mathrm{ed}$. Editora Autores Associados: Campinas, 1997.

Associados, 2011.

A história das ideias pedagógicas no Brasil. Campinas: Autores Pedagogia Histórico-Crítica. Campinas: Autores Associados, 2008. 